\title{
Tumor Identifier Portion or Totality
}

National Cancer Institute

\section{Source}

National Cancer Institute. Tumor Identifier Portion or Totality. NCI Thesaurus. Code

C117441.

A qualifier for the arrangement or apportioning of an entity within a body part, region or organ for the tumor identification. 